Www.jmscr.igmpublication.org

Index Copernicus Value: 79.54

ISSN (e)-2347-176x ISSN (p) 2455-0450

crossref DOI: https://dx.doi.org/10.18535/jmscr/v7i4.31

Journal Of Medical Science And Clinical Research

IGM Publication

An Official Publication of IGM Publication

Original Article

\title{
Evaluation of Liver Function and Symptomatic Relief after PTBD in Patients with Malignant Obstructive Jaundice
}

\author{
Authors \\ Kumar Jitendra $^{1}$, Jalaj Anjani ${ }^{2}$, Ojha Amit ${ }^{3}$, Yadav Pankaj ${ }^{4}$ \\ ${ }^{1}$ Resident, ${ }^{2}$ Professor, ${ }^{3}$ Associate Professor \\ Department of Surgery, Gajra Raja Medical College, Gwalior (M.P.) \\ ${ }^{4}$ Assocaite Professor, Department of Radiodiagnosis, Gajra Raja Medical College, Gwalior, MP, India
}

\begin{abstract}
Background: Obstructive jaundice is a surgical problem that occurs when there is an obstruction to the passage of conjugated bilirubin from liver cells to intestine. It is a challenging condition managed by general surgeons and contributes significantly to high morbidity and mortality. The management of obstructive jaundice poses diagnostic and therapeutic challenges to general surgeons practicing specially in resource limited area.

Aims and Objectives: To investigate the clinical outcome of percutaneous transhepatic biliary drainage in patients with malignant obstructive jaundice

To assess the effect on quality of life $(Q O L)$ and liver function in patients with malignant obstructive jaundice who have undergone PTBD.

Methods: From 2017 to 2018, 50 patients of malignant obstructive jaundice were taken and PTBD procedure was performed under USG and fluoroscopic guidance, using digital subtraction angiography machine at Department of Surgery, G.R. Medical College \&J.A. Group of Hospitals, Gwalior. Results were collected and statistical analysis was done to reach the final conclusion.

Results: Majority of the patients were females (68\%). Age of study cohort ranged from 36 to80 years. Majority of the patients had jaundice (100\%) as the most common symptom followed by pain in abdomen (82\%), Itching/ pruritus (52\%), Weakness (36\%), Anorexia/decreased appetite (40\%) and Yellowish discoloration of eye and urine (28\%). In our study PTBD was performed and we found that it was successful in first attempt in $90 \%$ of the patients. Percutaneous biliary stenting provided significantly better drainage with symptomatic relief of the symptoms and lower complication.

Conclusions: PTBD is an effective method of biliary tract decompression and it is animportant alternative to endoscopic drainage. Percutaneous drainage of biliary ducts decompresses mechanical jaundice and decreases typical serum markers of cholestasis. PTBD is indicated in patients with inoperable biliary tract malignancy with obstructive jaundice as a preferred palliative procedure.

Keywords: Malignant obstructive jaundice, carcinoma gall bladder, cholangiocarcinoma.
\end{abstract}

\section{Introduction}

Obstructive jaundice is a surgical problem that occurs when there is an obstruction to the passage of conjugated bilirubin from liver cells to intestine. Obstructive jaundice can be of benign and malignant etiologies. 
GB cancer is the most common malignancy of the gastrointestinal tract in women and most common cause of malignant surgical obstructive jaundice in northern India. ${ }^{(1)}$

Malignant obstructive jaundice can lead to hyper bilirubinemia, anorexia, pruritus, cholangitis, septicemia and liver failure. ${ }^{(2)}$

PTBD and stenting are emerging palliative treatment for inoperable malignant tumor with obstructive jaundice. Indications of PTBD in obstructive jaundice include:

- Cholangitis

- Pain attenuation

- Pruritus

- To decrease serum bilirubin before the initiation of chemotherapy

\section{Aims and Objectives}

1. To investigate the clinical outcome of percutaneous transhepatic biliary drainage in patients with malignant obstructive jaundice.

2. To assess the effect on quality of life (QOL) and liver function in pt. with malignant obstructive jaundice who have undergone ptbd.

\section{Materials and Method}

A prospective study was designed for a sample of 50 patients admitted at department of surgery, G.R. Medical College \& J.A. Group of Hospitals between February 2017 to January 2018.

All patients with malignant obstructive jaundice (serum bilirubin $>3 \mathrm{mg} / \mathrm{dl}$ ) except refusal to participate in study, patient with bismut. type iv block (multi segmental block), with massive ascites, patient with bleeding diathesis, patient with liver cirrhosis. all patients underwent detail history, physical examination, laboratory investigation, radiological investigation followed by preparation of PTBD then USG guided invasive procedure PTBD were done. Thereafter postoperative care and clinical observation followed by evaluation of laboratory investigation as well as complication of PTBD were noted.
During the preoperative period the following protocol were followed:

Assessment of coagulation profile like BT, CT, PT-INR, LFT, KFT, CBC, RBS, Inj. vit.k100mg OD $\mathrm{i} / \mathrm{m}$ for 3 days, Inj antibiotics $3^{\text {rd }}$ generation cephalosporin + metronidazole, NPO for $8 \mathrm{hr}$ before surgery, Inj atropine $0.5 \mathrm{mg} \mathrm{i} / \mathrm{m}$, Xylocaine sensitivity test, Test for sensitivity to contrast by $\mathrm{i} / \mathrm{m}$ injection, Correction of dehydration by parenteral fluid therapy.

\section{Operative Procedure}

- Ultrasonographic examination of the abdomen was done.

- Dilated intrahepatic bile duct and their position and size were noted

- A large dilated bile duct was selected for cannulation and the depth of the bile duct was assess and marked the site with marking pencil.

- The depth and direction of dilated IHBR from skin was confirmed.

- Then patient in supine position on OT table. ' $\mathrm{C}$ ' arm switched on.

- Then PTBD procedure was done in following steps:

Local anesthesia was infiltrated at the marked site.

A 18-G Chiba needle with sheath was inserted at mark site with appropriate direction of the dilated biliary duct. Correct position of the needle was confirmed by aspiration of bile, which was taken for biochemical, cytological analysis. Contrast was now injected and IHBR was seen under Carm. Chiba needle removed and 0.035 -inch guidewire introduced through the sheath in to the bile ducts and confirmed by correct placement confirm under ' $\mathrm{C}$ ' arm. Outer sheath was removed keeping guide wire in same place. Serial dilators were passed over the guide wire for the dilatation of tract. Finally pigtail catheter was passed over the guide wire and guide wire was removed. Then confirmation of pigtail catheter under $\mathrm{C}$-arm after injecting contrast (urograffin76\%) and by aspiration of bile. 


\section{Post-Operative Observations}

- After the procedure, all patients were monitored for vital signs, $\mathrm{O} 2$ saturation, liver and kidney functions post procedure and routine blood investigations were performed. Rehydration was considered paramount to protect liver and prevent infection.

- Cholangiogram after 2 days \& follow-up on 3 days, 1 week, 2, 3 and 4 week via evaluation of laboratory and radiological investigation.

\section{Results}

Present prospective study was performed on 50 patients of malignant Obstructive Jaundice patients. Following observations were made:

\section{Following observations were made}

1. Majority of the patients were females $(68 \%)$ had jaundice $(100 \%)$ as the most common symptom followed by pain in abdomen (82\%), Itching/ pruritus (52\%),
Weakness (36\%), Anorexia/ decreased appetite (40\%) and Yellowish discoloration of eye and urine (28\%).

2. Though PTBD is a palliative measure we found that it was successful in first attempt in $90 \%$ \&only $5(10 \%)$ needed second attempt, overall $89 \%$ of patients got relieved. P- value was calculated after determining the degree of freedom and using chi-square test. P-value was found to be significant in our study.

3. In present study out of 50 patients 5 patient died $(10 \%)$. Out of those, maximum were female $(60 \%)$, had fever (60\%), all have Grade IV jaundice $(100 \%)$, and itching $(60 \%)$. Mean bilirubin, SGOT, SGPT and A LP was 21, 170.80, 176.6 and 1104. 40 respectively.

4. In present study shows a positive impact of quality of life of patients after PTBD.

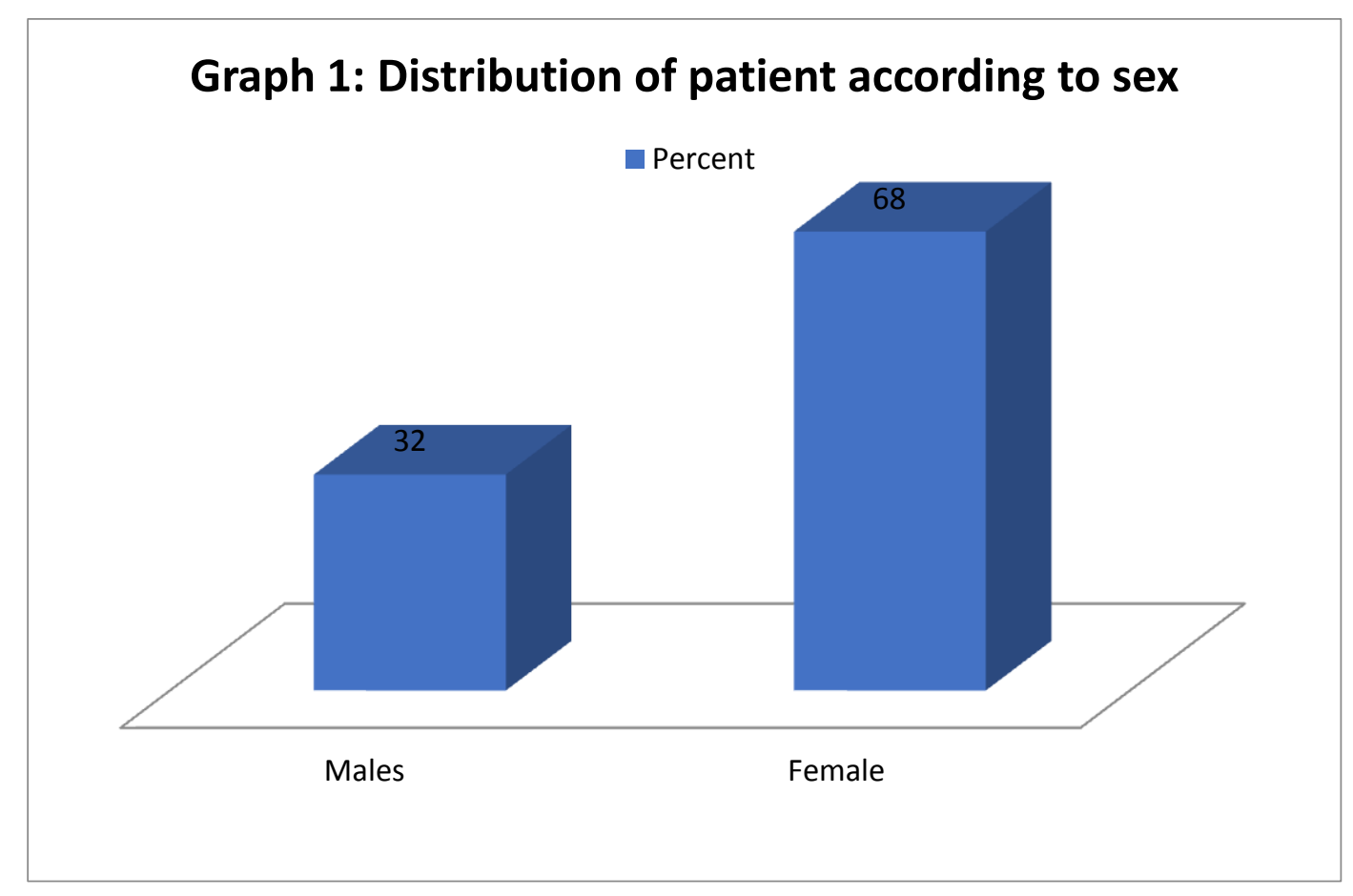

Table 1: Distribution of patient according to sex

\begin{tabular}{|l|c|c|}
\hline Sex & Frequency & Percentage \\
\hline Males & 16 & 32 \\
\hline Female & 34 & 68 \\
\hline
\end{tabular}


Table 2: Distribution of no. of patients who get relief of their symptoms

\begin{tabular}{|c|c|c|c|c|c|c|c|c|}
\hline \multirow{2}{*}{\multicolumn{2}{|c|}{ Symptoms }} & \multirow[b]{2}{*}{$\begin{array}{l}\text { Before } \\
\text { PTBD }\end{array}$} & \multicolumn{5}{|c|}{ After PTBD } & \multirow{2}{*}{$\begin{array}{c}\mathbf{P} \\
\text { value }\end{array}$} \\
\hline & & & $\begin{array}{c}3^{\text {rd }} \\
\text { Day }\end{array}$ & $\begin{array}{c}1^{\text {st }} \\
\text { week } \\
\end{array}$ & $\begin{array}{c}2^{\text {nd }} \\
\text { week }\end{array}$ & $\begin{array}{c}3^{\text {rd }} \\
\text { week } \\
\end{array}$ & $\begin{array}{c}4^{\text {th }} \\
\text { week } \\
\end{array}$ & \\
\hline \multirow{4}{*}{ Jaundice } & Grade I & 0 & 0 & 0 & 0 & 0 & 3 & \\
\hline & Grade II & 0 & 0 & 0 & 0 & 6 & 22 & 0.001 \\
\hline & Grade III & 0 & 0 & 18 & 39 & 37 & 19 & 0.001 \\
\hline & Grade IV & 50 & 50 & 30 & 7 & 2 & 01 & 0.001 \\
\hline \multicolumn{2}{|c|}{ Pain in abdomen } & 41 & 05 & 20 & 08 & 03 & 01 & 0.019 \\
\hline \multicolumn{2}{|c|}{ Itching/ pruritus } & 26 & 0 & 0 & 3 & 5 & 14 & 0.034 \\
\hline \multicolumn{2}{|c|}{ Fever } & 8 & 2 & 5 & 0 & 0 & 0 & 0.0004 \\
\hline \multicolumn{2}{|c|}{ Yellowish discoloration of eye and urine } & 14 & 0 & 0 & 0 & 2 & 9 & 0.245 \\
\hline \multicolumn{2}{|c|}{ Nausea } & 22 & 0 & 0 & 0 & 10 & 5 & 0.013 \\
\hline \multicolumn{2}{|l|}{ Vomiting } & 5 & 0 & 2 & 1 & 0 & 0 & 0.852 \\
\hline \multicolumn{2}{|c|}{ Anorexia/decreased appetite } & 20 & 0 & 0 & 3 & 4 & 9 & 0.002 \\
\hline \multicolumn{2}{|c|}{ Acholic stool } & 6 & 0 & 0 & 0 & 0 & 0 & 0.021 \\
\hline \multicolumn{2}{|c|}{ Palpable abdominal mass } & 6 & 0 & 0 & 0 & 0 & 0 & NA \\
\hline \multicolumn{2}{|c|}{ others } & 0 & 0 & 0 & 0 & 0 & 0 & NA \\
\hline
\end{tabular}

Note: P value - significant

\section{Graph 2: Distribution of no. of patients who get reieve of their symtpoms (jaundice) after PTBD}

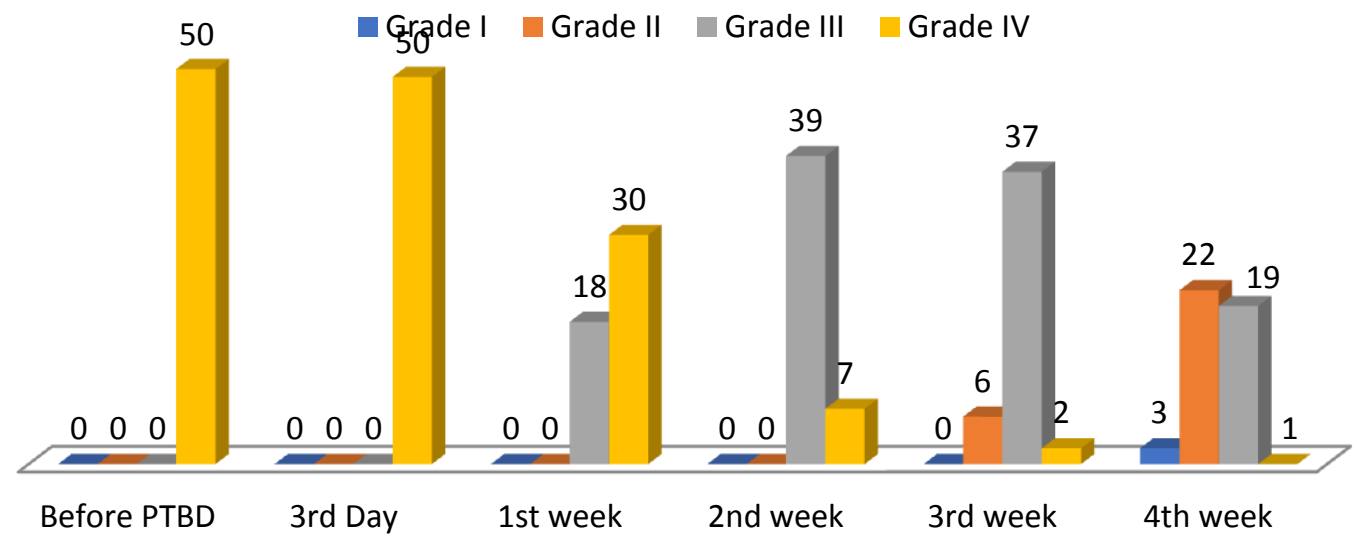

Grading system has been developed by the Cancer Therapy Evaluation Program of the National Cancer Institute (NCI) of the National Institutes of Health, which is referred to as the Common Toxicity Criteria for Adverse Events, version 4.0: CTCAEv4. In this system, the following levels are used to assess severity, with the values expressed as multiples of the upper limit of the normal range (ULN).
(U.S. National Library of Medicine, 8600 Rockville Pike, Bethesda, MD 20894 National Institutes of Health, U.S. Department of Health \& Human Services Graphic Courtesy of The Scientific Consulting Group, Inc,)

\begin{tabular}{|l|c|c|c|c|c|}
\hline FEATURE & Grade 0 & Grade 1 & Grade 2 & Grade 3 & Grade 4 \\
\hline SGPT & Normal & $>1.0-2.5$ & $>2.5-5.0$ & $>5.0-20$ & $>20$ \\
\hline SGOT & Normal & $>1.0-2.5$ & $>2.5-5.0$ & $>5.0-20$ & $>20$ \\
\hline Alkaline Phosphatase & Normal & $>1.0-2.5$ & $>2.5-5.0$ & $>5.0-20$ & $>20$ \\
\hline Bilirubin & Normal & $>1.0-1.5$ & $>1.5-3.0$ & $>3.0-10$ & $>10$ \\
\hline
\end{tabular}


Table 3: Improvement in LFT's after PTB

\begin{tabular}{|l|c|c|c|c|c|c|c|}
\hline \multirow{2}{*}{$\begin{array}{l}\text { Para- } \\
\text { meters }\end{array}$} & \multirow{2}{*}{$\begin{array}{c}\text { Pefore } \\
\text { PTBD }\end{array}$} & \multicolumn{7}{|c|}{ After PTBD } & \multirow{2}{*}{ P value } \\
\cline { 3 - 7 } & $\mathbf{3}^{\text {rd }}$ Day & $\mathbf{1}^{\text {st }}$ week & $\mathbf{2}^{\text {nd }}$ week & $\mathbf{3}^{\text {rd }}$ week & $\mathbf{4}^{\text {th }}$ week & \\
\hline $\begin{array}{l}\text { Bilirubin } \%) \\
\text { ALP } \\
(I U / L)\end{array}$ & $20.2 \pm 4.4$ & $16.0 \pm 3.9$ & $12.1 \pm 3.2$ & $8.8 \pm 2.7$ & $6.2 \pm 2.5$ & $3.5 \pm 1.2$ & $<0.001$ \\
\hline $\begin{array}{l}\text { SGOT } \\
\text { (IU/L) }\end{array}$ & $1137 \pm 503.1$ & $952.7 \pm 407.48$ & $739.4 \pm 370.8$ & $618.9 \pm 286.3$ & $437.4 \pm 216.5$ & $291.2 \pm 134.7$ & $<0.001$ \\
\hline $\begin{array}{l}\text { SGPT } \\
(I U / L)\end{array}$ & $198.1 \pm 72.0$ & $171.3 \pm 68.3$ & $121.6 \pm 47.1$ & $97.5 \pm 37.4$ & $77.9 \pm 27.5$ & $90.1 \pm 201.4$ & $<0.001$ \\
\hline
\end{tabular}

Serum bilirubin was reduced from $20.2 \pm 4.4$ before PTBD to $3.5 \pm 1.2$ at the end of $4^{\text {th }}$ week after PTBD. Similarly ALP was reduced from $1137 \pm 503.1$ before PTBD to $291.2 \pm 134.7$ at the end of $4^{\text {th }}$ week after PTBD. SGOT and SGPT were also reduced from 192.1 \pm 72.0 and 198.2 \pm 94.5 respectively before PTBD to $90.1 \pm 201.4$ and $54.3 \pm 23.1$ at the end of $4^{\text {th }}$ week after PTBD.

Table 4: Complications of PTBD

\begin{tabular}{|c|c|c|}
\hline Complications & Number of cases & Percentage \\
\hline Abdominal Pain & 4 & 8 \\
\hline Bleeding & 0 & 0 \\
\hline Septicemia & 0 & 0 \\
\hline Procedure related death & 0 & 0 \\
\hline $\begin{array}{l}\text { Cholangitis (patients having pre operative Cholangitis were } \\
\text { separately recorded) }\end{array}$ & 9 & 18 \\
\hline Catheter dislodgement & 4 & 8 \\
\hline PTBD unsuccessful-procedure abandoned & 0 & 0 \\
\hline Pericatheter leakage & 4 & 8 \\
\hline PTBD Blockage & 10 & 20 \\
\hline Blood mix with bile in pigtail catheter & 4 & 8 \\
\hline Pigtail extrusion & 1 & 2 \\
\hline Pigtail malfunction & 1 & 2 \\
\hline
\end{tabular}

\section{Discussion}

Majority of the patients were females (68\%) followed by males (32\%). Contrary to present study findings Nimura et al, Pollock et al, Blungart et al showed male preponderance. This high percentage of carcinoma gallbladder in females can be explained by the factors like pregnancy, estrogen therapy, use of oral contraceptive pills, which are specific only in females. This increase biliary cholesterol secretion and susceptibility to cholesterolstasis, biliary Stasis and infection and prolonged period of untreated disease leads to Development of carcinoma gall bladder. Mean age of study cohort was $60.72 \pm 12.61$ years which ranged from 36 to80 years. Study done by Y. Nimura et al (69 yr), Patricia K. Joseph et al (71 yr) and Thomas W.
Pollock et al (64 yr) also reported similar mean age. ${ }^{(3)}$

Elevated serum bilirubin (>3 $\mathrm{g} / \mathrm{dl})$ clinically presents as jaundice. Hyper bilirubinemia impedes the initiation/continuation of chemotherapy in certain malignancies. ${ }^{(4)}$ In present study majority of the patients had jaundice $(100 \%)$. Pruritus is a common accompaniment in malignant obstructive jaundice which may be disproportionate to the jaundice and usually alleviated by the drainage of even a single liver segment. ${ }^{(4)}$ In present study pain in abdomen in $82 \%$ patients at baseline, itching/ pruritus was reported in $52 \%$ patients and anorexia/decreased appetite in $40 \%$ and yellowish discoloration of eye and urine in $28 \%$, Nausea in $44 \%$, Acholic stool $12 \%$ and palpable abdominal mass $12 \%$. 
Pain and anorexia further deteriorate the quality of life which may be relieved to some extent by restoring physiological enterohepatic circulation by various drainage means (vide supra). ${ }^{(5,6,7)}$

In present study PTBD was performed and we found that it was successful in first attempt in $90 \%$ of the patients. Only for $5(10 \%)$ patients needed second attempt. Knapa et al reported their experience of biliary drainage with the aid of percutaneous transhepatic method and simultaneous assessment of method effectiveness and safety. They have reported that the technical success was achieved in 168 patients $(90.7 \%$ )of the procedures. In 15 patients $(8.1 \%)$, drainage application was ineffective. ${ }^{(8)}$ They also reported that repeat procedures were required in 24 $(12.9 \%)$ patients. $^{(8)}$ Saluja et al compared unilateral PTBD and ES and reported that the successful stent insertion rate was higher in the PTBD group (93\%) compared with the ES group $(82 \%) .{ }^{(9)}$ The procedure can be performed either via right (subcostal or intercostal) or left ductal (subxiphoid) approach. Selection of appropriate sided duct (right or left) is a personal preference, although there are certain advantages and disadvantages of both. ${ }^{(4)}$ Saluja et al compared unilateral PTBD and ES and reported that successful drainage was significantly more in the PTBD group than in the ES group (89\% vs $41 \%$, $\mathrm{P}=.001$ ). They have found early complication rate was significantly more common in the ES group ( $52 \%$ vs $18 \%, \mathrm{P}=.04$ ); and early cholangitis was the most common complication in the ES group ( $48 \%$ vs $11 \%, \mathrm{P}=.002$ ). This has been reported as the commonest Complications in most studies Carrasco et al-47\%; Yee et al-30\%; Cohan et al$54 \%$; Sirinek et al-61.53\%; This study $17.39 \%$. ${ }^{(9)}$

Pinol et al. They have showed higher successful drainage $(71 \%$ vs $42 \%, \mathrm{P}=.03)$ but more complications (61\% vs 35\%) with PTBD as compared with endoscopic drainage ${ }^{10}$. This higher success rates in present study could be due to the staged technique used for PTBD; an internal or external drainage was kept for 48 hours followed by an internal stent placement after one week later.

Matri et al in their report showed that the technical success was achieved in $98 \%$ of patients. ${ }^{11}$

In present study, most common postoperative complication was PTBD blockage in 10 patients (20\%), followed by cholangitis in 9 patients $(18 \%)$.

In present study out of 50 patients analysed, there was a major effect on the quality of life of patients which belonged to grade 4 jaundice, had improvement in their lifestyle in respect to factors analysed in follow up such as itching which was found in about $52 \%$ patients, reduced dramatically and at the end of $4^{\text {th }}$ week about $85 \%$ got relief. Similarly $40 \%$ patients enrolled in our study had anorexia out of which $80 \%$ got relief at the end of 4 weeks. Fever, nausea, vomiting all these complaints described the patients during enrollment got dramatically decreased at the the end of 4th week.

Thus our study shows a positive impact in the quality of life of patients after PTBD, approximately $90 \%$ patients got relief from the various complaints analysed at regular follow up. Present study has few limitations. First cross sectional nature of the present study was the main limitation which restricts the use of present study findings to large population. Second is the small sample size; a large randomize clinical study is required to strengthen the present study findings.

\section{Conclusion}

PTBD is an important alternative to endoscopic drainage. It decompresses mechanical jaundice and decreases typical serum markers of cholestasis and is indicated in patients with inoperable biliary tract malignancy with obstructive jaundice as a preferred palliative procedure.

\section{References}

1. National Cancer Registry Programme. Two-year report of the Population Based Cancer Registries. New Delhi: Indian 
Council of Medical Research 2002; 19971998.

2. Brountzos EN, Ptochis N, Panagiotou I, Malagari K, Tzavara C, Kelekis D. A survival analysis of patients with malignant biliary strictures treated by percutaneous metallic stenting. Cardiovasc Intervent Radiol. 2007;30:66-73.

3. M. Nagino, N. Hayakawa, Y. Nimura, M. Dohke, S. Kitagawa. Percutaneous Transhepatic biliary drainage in patients with malignant biliary obstruction of the Hepatic confluence Hepatic Gastroenterology 1992;39:296-300.

4. Chandrashekhara SH, Gamanagatti S, Singh A, Bhatnagar S. Current status of percutaneous transhepatic biliary drainage in palliation of malignant obstructive jaundice: A review. Indian J Palliat Care 2016;22:378-87.

5. Ballinger $\mathrm{AB}, \mathrm{McHugh} \mathrm{M}$, Catnach $\mathrm{SM}$, Alstead EM, Clark ML. Symptom relief and quality of life after stenting for malignant bile duct obstruction. Gut 1994;35:467-70.

6. Abraham NS, Barkun JS, Barkun AN. Palliation of malignant biliary obstruction: A prospective trial examining impact on quality of life. Gastrointest Endosc 2002;56:835-41.

7. Van Laethem JL, De Broux S, Eisendrath $\mathrm{P}$, Cremer $\mathrm{M}$, Le Moine $\mathrm{O}$, Devière $\mathrm{J}$. Clinical impact of biliary drainage and jaundice resolution in patients with obstructive metastases at the hilum. Am J Gastroenterol. 2003;98:1271-7.

8. Knapa D, Natalia Orlecka Renata Judka Aleksandra Juzab Michał Drabek Maciej Honkowicz et al. Biliary duct obstruction treatment with aid of percutaneous transhepatic biliary drainage. Alexandria
Journal of Medicine. Volume 52, Issue 2, June 2016, Pages 185-191

9. Saluja SS, Gulati M, Garg PK, Pal H, Pal S, Sahni P, Chattopadhyay TK. Endoscopic or percutaneous biliary drainage for gallbladder cancer: a randomized trial and quality of life assessment. Clin Gastroenterol Hepatol. 2008 Aug;6(8):944-950.e3.

10. Pinol V, Castells A, BordasJM, et al. Percutaneous self-expanding metal stents versus endoscopic polyethylene endoprostheses for treating malignant biliary obstruction: randomized clinical trial. Radiology 2002;225:27-34.

11. Matri M, FarhatLB, Moussa IM, Aloui W, Hendaoui L, et al. Percutaneous biliary drainage: complications and efficiency at short and mean terms: about 50 cases. European Society of Radiology 2016:1-17. 